\title{
Production of $\alpha$-Amylase by Aspergillus terreus NCFT 4269.10 Using Pearl Millet and Its Structural Characterization
}

\author{
Bijay K. Sethi ${ }^{1}$, Arijit Jana ${ }^{2}$, Prativa K. Nanda ${ }^{3}$, Pradeep K. DasMohapatra ${ }^{2}$, \\ Santi L. Sahoo ${ }^{1}$ and Jayanta Kumar Patra ${ }^{4 *}$ \\ ${ }^{1}$ Microbiology Research Laboratory, Post Graduate Department of Botany, Utkal University, Bhubaneswar, India, \\ ${ }^{2}$ Department of Microbiology, Vidyasagar University, Midnapore, India, ${ }^{3}$ Department of Botany, Saila Bala Women's College, \\ Cuttack, India, ${ }^{4}$ Research Institute of Biotechnology \& Medical Converged Science, Dongguk University, Goyang, \\ South Korea
}

OPEN ACCESS

Edited by:

Agnieszka Ludwików, Adam Mickiewicz University in Poznań, Poland

Reviewed by: Armen Trchounian,

Yerevan State University, Armenia Taras P. Pasternak, Institute of Biology II, Germany

*Correspondence: Jayanta Kumar Patra jayantakpatra@gmail.com

Specialty section: This article was submitted to

Plant Biotechnology, a section of the journal Frontiers in Plant Science

Received: 11 March 2016 Accepted: 25 April 2016 Published: 18 May 2016

Citation Sethi BK, Jana A, Nanda PK, DasMohapatra PK, Sahoo SL and Patra JK (2016) Production of $\alpha$-Amylase by Aspergillus terreus NCFT 4269.10 Using Pearl Millet and Its Structural Characterization.

Front. Plant Sci. 7:639.

doi: 10.3389/fpls.2016.00639
In this investigation, Aspergillus terreus NCFT4269.10 was employed in liquid static surface (LSSF) and solid state (SSF) fermentation to assess the optimal conditions for $\alpha$-amylase biosynthesis. One-variable-at-a-time approach (quasi-optimum protocol) was primarily used to investigate the effect of each parameter on production of amylase. The maximum amylase production was achieved using pearl millet (PM) as substrate by SSF $\left(19.19 \pm 0.9 \mathrm{Ug}^{-1}\right)$ and also in presence of $1 \mathrm{mM}$ magnesium sulfate, $0.025 \%(\mathrm{w} / \mathrm{v})$ gibberellic acid, and $30 \mathrm{mg} / 100 \mathrm{ml}(\mathrm{w} / \mathrm{v})$ of vitamin $\mathrm{E}$ ( 60 -fold higher production of amylase) with the initial medium $\mathrm{pH}$ of 7.0 and incubation at $30{ }^{\circ} \mathrm{C}$ for $96 \mathrm{~h}$. In addition, maltose, gelatin and isoleucine also influenced the $\alpha$-amylase production. Amylase was purified to homogeneity with molecular mass around $15.3 \mathrm{kDa}$. The enzyme comprised of a typical secondary structure containing $\alpha$-helix (12.2\%), $\beta$-pleated sheet (23.6\%), and $\beta$-turn (27.4\%). Exploitation of PM for $\alpha$-amylase production with better downstream makes it the unique enzyme for various biotechnological applications.

Keywords: $\alpha$-amylase, Aspergillus terreus, liquid static surface fermentation, pearl millet, solid state fermentation

\section{INTRODUCTION}

Amylases, the glycoside hydrolases discovered and isolated by Anselme Payen in 1833 are omnipresent enzymes, almost produced by many animals, plants, bacteria, molds, and fungi; but the mainstream applications of $\alpha$-amylase in many modern biotechnological purposes are basically of bacterial and fungal origin. Fungal $\alpha$-amylases have been achieved the pivotal place in "high-flying industrial enzymes" as they make enable the catalysis at wide range of both $\mathrm{pH}$ and temperature, possess higher degree of substrate specificity, may or may not demand cofactors and can catalyze an array of biochemical processes. The amylase family comprises of three major groups, namely $\alpha$-amylase (EC 3.2.1.1), $\beta$-amylase (EC 3.2.1.2), and glucoamylase (EC 3.2.1.3). The $\alpha$-amylase and all include a huge proportion of tyrosine and tryptophan in the enzyme protein and denature at around $60^{\circ} \mathrm{C}$. The $\alpha$-amylase is an extracellular endo-glycoprotein having single polypeptide chain of 475 residues, two - $\mathrm{SH}$ groups and 4 disulfide bridges with a compactly bound $\mathrm{Ca}^{2+}$. It subsists in two forms (I and II) exhibiting identical properties and differing only in electrophoretic mobility (Welch and Grahm, 2004). The $\alpha$-amylase splits starch at random locations to eventually yield maltotriose and maltose, glucose and "limit dextrin" from amylopectin 
by cleaving the 1, 4- $\alpha$-D-glucosidic bonds in neighboring glucose units in the straight chain of amylose (Pandey et al., 2000). Based on their action specificity toward $\alpha$-glucan chains they are either exo-acting ( $\alpha$-amylase and glucoamylase) or endoacting in nature. All enzymes belonging to $\alpha$-amylase cluster are classified into the GH 13 family and their arrangement contains a $(\beta / \alpha)$ barrel with Glu as a proton donor and Asp as a nucleophile on its catalytic sites. They are further grouped into eight sub families (Schaechter, 2009). Amylases are the second sort of enzymes employed in the formulation of detergents and contribute $\sim 25 \%$ to the world enzyme trading (Ikram et al., 2003).

Aspergillus species biosynthesize a large variety of extracellular enzymes of which $\alpha$-amylases are of world-wide interest in fermentation, food, pharmaceutical, textile, and paper industries (Pandey et al., 2000; Bhargav et al., 2008). They are exploited for hydrolysis in the starch liquefaction process that alters starch into fructose and glucose syrup. They are also implemented in partial replacement of expensive malt in the brewing industries, improving flour quality in the baking industries, manufacturing of modified starches for the paper industries and for elimination of starch in the production of textiles (desizing).

In contemporary industrial processes, fungal $\alpha$-amylases are of great significance owing to their easy extraction and separation from mycelium. Now-a-days, both submerged ( $\mathrm{SmF}$ ) and solid state fermentation (SSF) processes are usually adopted for enzyme biosynthesis with certain alterations. The industrial production of enzymes for biotechnological exploitation, isolation and its characterization, searching of novel efficient strains is an assiduous exercise (Kumar et al., 2002). To reiterate, the enzyme biosynthesis by filamentous fungi is reported to be influenced by numerous factors, such as $\mathrm{pH}$, temperature (Ferreira Costa and Peralta, 1999), carbon and nitrogen sources (George et al., 1999). The activity of enzyme mostly relies on the availability of huge surface area and requires intense mild conditions. They are generally biosynthesized by SmF owing to its obvious significance in product recovery regardless of costly of ingredients of medium. Nevertheless, SSF offers many advantages over SmF. However, studies on fungal $\alpha$-amylase, lipase, pectinase and proteases especially in developing countries are primarily focused on Aspergillus spp. and Rhizopus spp., probably due to their ubiquity and nonpretentious nutritional requirements. Substrates like vegetable waste, rice husk, banana peels (Khan and Yadav, 2011), wheat bran (Negi and Banerjee, 2010), date wastes (Acourene and Ammouche, 2012), sugarcane baggase (Roses and Guerra, 2009), wheat straw, rye straw, corncob leaf, oil cakes, and many others (Bhargav et al., 2008) have been utilized for the biosynthesis of amylases. Consequently, SSF process is of particular economic concern for such countries which have generation of huge plant biomass and agro-industrial wastes. In that scenario, India revealed its superiority. The most tedious job in optimization of fermentation condition for enhanced biosynthesis is the interference of many medium ingredients and various cultural parameters. Further, manual approach toward optimization of parameters using one-variable-at-a-time (OVAT) method is also effortful and time consuming. Nonetheless, the culture amendment and process parameter optimization is obligatory in achieving enhanced production of industrial enzymes.

Therefore, in this study, different fermentation parameters were appraised, optimized and developed for enhanced production of industrially imperative $\alpha$-amylase by Aspergillus terreus NCFT 4269.10 using various medium composition and fermentation conditions. However, the attempts made may be of great industrial significance owing to the effective waste utilization and economic production which could lead $\alpha$-amylase toward new industrial applications.

\section{MATERIALS AND METHODS}

\section{Materials and Chemicals}

Different agro-residues such as mustard oil cake (MoC), neem oil cake (NoC), groundnut oil cake (GnoC), black gram peels (BGP), green gram peels (GGP), chickling vetch peels/grass pea peels (CVP) wheat bran (WB), pearl millet residues (PMR), finger millet waste (FMW), broken rice (BR), banana peels (BP), apple pomace (AP), and orange peels (OP) were purchased from the local market of Bhubaneswar, Odisha, India. Substrates were dried in the laboratory at $60^{\circ} \mathrm{C}$ up to $48 \mathrm{~h}$, ground to fine powder, sieved and kept in sterile containers until used. All chemicals implemented in this study were of analytical reagent (AR) grade and purchased from Sigma, Hi-Media Limited, SRL Pvt. Limited and Merck India Limited (Mumbai, India).

\section{Proximate Composition Analysis of Substrates}

Percentage of moisture content was determined by oven drying to a constant weight, protein by Lowry et al. (1951), ash by direct analysis, water holding capacity (WHC) and total carbohydrate and starch were calculated by Anthrone reagent method. For estimation of calcium, it was precipitated as calcium oxalate, dissolved in hot dilute $\mathrm{H}_{2} \mathrm{SO}_{4}$ and titrated against standard potassium permanganate (Oser, 1965). Analysis of metals was performed with Atomic Absorption Spectrophotometer.

\section{Inoculum Development and Fermentation}

A potato dextrose agar (PDA) slant culture of $A$. terreus NCFT 4269.10 (GenBank Accession No.: KT222271; Sethi et al., 2013a) producing $\alpha$-amylase was streaked out and thoroughly mixed in $5.0 \mathrm{ml}$ of sterile deionised water. Then, from the spore suspension, $1.0 \mathrm{ml}$ was inoculated to fresh sterilized potato dextrose broth medium for development of working culture and incubated at $30 \pm 1^{\circ} \mathrm{C}$ up to 7 days to attain about $5.0 \times 10^{8}$ spores $\mathrm{ml}^{-1}$. For the entire study, $1 \times 10^{7}$ spores $\mathrm{ml}^{-1}$ was used as inoculum to carry out the fermentation process (Sethi et al., 2013b).

To identify the potential substrate for biosynthesis of $\alpha$ amylase, liquid static surface fermentation (LSSF) and solid substrate fermentation (SSF) were performed by constituting the medium with each of the pre-processed substrates (10 g) as fermentation medium ingredients. In $150 \mathrm{ml}$ Erlenmeyer flask, $50 \mathrm{ml}$ of sterilized fermentation medium having either MoC, GnoC, NoC, BGP, GGP, WB, BP, OP, PM, and FM as substrates. Under static condition, these media were inoculated 
with $1 \times 107$ spores $\mathrm{ml}^{-1}$ as inoculum and incubated at 30 $\pm 1^{\circ} \mathrm{C}$. Similarly, $5 \mathrm{~g}(\mathrm{w} / \mathrm{w})$ of each substrate was placed in Erlenmeyer flasks $(250 \mathrm{ml})$ and moisture content was adjusted using $8 \mathrm{ml}$ of minimal salt solution and autoclaved at $15 \mathrm{psi}$ $\left(121^{\circ} \mathrm{C}\right)$. The cooled sterilized media were aseptically inoculated with $1 \times 107$ spores $\mathrm{ml}^{-1}$ and incubated at $30 \pm 1^{\circ} \mathrm{C}$ with intermittent observation. After $96 \mathrm{~h}$, fermented media (both LSSF and SSF) were processed for down streaming of crude $\alpha$-amylase as per the method of Sethi et al. (2013b). After preliminary screening, further, LSSF and SSF were performed using suitable substrate for extracellular production of $\alpha$-amylase. The crude $\alpha-$ amylase recovered was stored at $-20^{\circ} \mathrm{C}$ for further analysis. Dry weight of the fungal biomass was estimated after exposing the wet biomass at $80^{\circ} \mathrm{C}$ in hot air oven up to $24 \mathrm{~h}$.

\section{Scaling up of Various Fermentation Parameters for Enhanced Biosynthesis of $\alpha$-Amylase}

To optimize different fermentation parameters (environmental, nutritional, and others) for enhanced extracellular enzyme synthesis by $A$. terreus, different fermentation parameters were studied using SSF and LSSF at various pHs (3-10), temperature $\left(24-45^{\circ} \mathrm{C}\right.$ at $3^{\circ} \mathrm{C}$ interval), incubation period $(24-168 \mathrm{~h})$, at different carbon sources [glucose, maltose, lactose, mannose, sucrose, starch, cellulose $(1.0 \%, \mathrm{w} / \mathrm{w})]$, organic nitrogen sources [peptone, tryptone, gelatin, yeast extract, beef extract, $(1.0 \%, \mathrm{w} / \mathrm{w})]$, and inorganic nitrogen sources [ammonium persulphate, ammonium nitrate, ammonium sulfate, ammonium chloride, sodium nitrate, and urea $(1.0 \%$ $\mathrm{w} / \mathrm{w})$ ], amino acids [Alanine, Proline, Valine, Aspartic acid, Methionine, Glutamate, L-lysine, Cysteine, Histidine, Phenyl alanine, Isolucine, Threonine, Tryptophan, Agrinine, Leucine, Glycine, and Serine $(1.0 \mathrm{mM} / 100 \mathrm{ml})]$, metal ions $\left[\mathrm{Zn}^{2+}, \mathrm{K}^{+}\right.$, $\mathrm{Ag}^{2+}, \mathrm{Fe}^{2+}, \mathrm{Mg}^{+}, \mathrm{Cu}^{2+}, \mathrm{Mn}^{+}, \mathrm{Ca}^{+}, \mathrm{Hg}^{+}$, and Ethylene diamine tetra acetic acid (EDTA) $(1.0 \mathrm{mM} / 100 \mathrm{ml})]$, antioxidant vitamins [Vitamin C, Riboflavin, Folic acid and Vitamin E (10$50 \mathrm{mg} / 100 \mathrm{ml}$ )], growth regulators [Gibberellic acid, Kinetin, 6-Benzylaminopurine and 2,4-Dichlorophenoxyacetic acid $(0.0025 \mathrm{mg} / \mathrm{g}, \mathrm{w} / \mathrm{w})$ ] combined agro-wastes [Pearl millet: oat, Pearl millet: finger millet, Finger millet: oat at 1:9, 3:7, 5:5, 7:3, 9:1 ratio, respectively, for each combination], inoculum size (2-10\%) and initial moisture content $(20-100 \%)$. The effect of time of soaking on fermented products (1-96 h), extraction at repeated cycle and various extractants were also optimized to develop an efficient and cheaper protocol for the recovery of $\alpha$-amylase. The strategy followed was to optimize one variable-at-a-time (OVAT), independent of the others and subsequently optimal conditions were employed in all experiments.

\section{Purification of $\alpha$-Amylase}

The crude culture filtrate $(\sim 500 \mathrm{ml})$ was precipitated by gradual addition of $40-80 \%$ ammonium sulfate $\left[\left(\mathrm{NH}_{4}\right) 2 \mathrm{SO}_{4}\right]$ with constant stirring by a magnetic stirrer at $4^{\circ} \mathrm{C}$ up to $24 \mathrm{~h}$. Each precipitate was separated from the supernatant by centrifugation at $10,000 \times \mathrm{g}$ for $15 \mathrm{~min}$ at $4^{\circ} \mathrm{C}$. After centrifugation, the supernatant was decanted and the solid precipitate was dissolved in phosphate buffer $\left(\mathrm{pH}\right.$ 6.5) at a ratio of $0.1 \mathrm{~g} \mathrm{ml}^{-1}$ so as to obtain 10-times more concentrated enzyme solution (Jana et al., 2013). Thereafter, ammonium sulfate precipitated enzyme solution was dialyzed for $24 \mathrm{~h}$ at $4^{\circ} \mathrm{C}$ with incessant stirring against a large volume (1 L capacity) of phosphate buffer $(\mathrm{pH}$ 6.5). To maintain solute gradient, the buffer used for dialysis was replaced with fresh buffer at every $2 \mathrm{~h}$ of interval so as to establish the concentration gradient. Then, the dialyzed $\alpha$ amylase was put onto the Sephadex G-100 column $(2.5 \times 70$ $\mathrm{cm}$ ) and elution was performed using $50 \mathrm{mM}$ phosphate buffer $\left(\mathrm{pH}\right.$ 6.5) with the flow rate of $1 \mathrm{ml} \mathrm{min}^{-1}$. Fractions attaining $2 \mathrm{ml}$ each were collected for total protein estimation (Lowry et al., 1951). The enzyme fractions displaying maximum absorbance at $750 \mathrm{~nm}$ were pulled together and estimated its enzyme activity. The enzyme fractions having higher enzyme activity were mixed in one tube, lyophilized and preserved at $-20^{\circ} \mathrm{C}$ for further analysis.

\section{Amylase Assay and Protein Quantification}

Amylase activity was measured at $540 \mathrm{~nm}$ as per Bernfeld (1955) method. One unit of $\alpha$-amylase activity was represented as the amount of $\alpha$-amylase that produces $1 \mu \mathrm{mol}$ of maltose at $1 \mathrm{~min}$ under the assay conditions.

Total protein content of both crude and purified $\alpha$-amylase was estimated as per the Lowry et al. (1951) method taking bovine serum albumin as the standard.

\section{SDS-PAGE and Zymographic Analysis}

Both crude and purified $\alpha$-amylase was subjected to $10 \%$ SDS-PAGE for estimation of molecular weight of the enzyme (Laemmli, 1970). Band(s) on the gels were visualized using a staining solution [Coomassie-Brilliant Blue R-250-0.1\% (w/v), methanol-50\% (v/v), glacial acetic acid-7\% (v/v), and milli Q distilled water- $43 \mathrm{ml}$ ] for $90 \mathrm{~min}$ at room temperature followed by destaining with $30 \%(\mathrm{v} / \mathrm{v})$ methanol, $7 \%(\mathrm{v} / \mathrm{v})$ acetic acid, and $63 \mathrm{ml}$ milli $\mathrm{Q}$ distilled water until the bands was became clear. Bio-Rad Gel documentation system was used to analyze the relative positions of bands. Various standard molecular weight protein markers in a range of $7-175 \mathrm{kDa}$ (Bangalore Genei Ltd.) were used for SDS-PAGE analysis. For the zymographic analysis, a $10 \%$ non-denaturing gel was run in a discontinuous buffer system using $0.5 \mathrm{M}$ Tris- $\mathrm{HCl}$ (running buffer having $\mathrm{pH} 9.1$ ) at $4^{\circ} \mathrm{C}$. The gel was kept for $1 \mathrm{~h}$ at $30^{\circ} \mathrm{C}$ in soluble starch solution $(2 \%, \mathrm{w} / \mathrm{v})$ prepared using phosphate buffer $(0.2 \mathrm{M} ; \mathrm{pH} 6.5)$. The band was visualized by staining the gel using an acidic iodine solution (0.2\% I2 and 2\% KI in 0.2 N HCl; Hames, 1990).

\section{Circular Dichroism (CD) Spectroscopy}

Secondary structure of $\alpha$-amylase was confirmed using Circular dichroism spectroscopic analysis (Jasco, J-810, USA) by controlling the temperature with a Peltier type cell holder. Purified enzyme sample of $10 \mu \mathrm{l}(1 \mathrm{mg} / \mathrm{ml})$ solution was pipetted into a quartz cuvette with a $1 \mathrm{~mm}$ path-length at room temperature under constant nitrogen spurging at the far UV region (200-360 nm). The protein far-UV spectra were recorded by signal averaging of five spectra, with a step resolution of 0.1 $\mathrm{nm}$ and a speed of $100 \mathrm{~nm} / \mathrm{min}$. The protein signal was obtained 
by subtracting buffer spectrum from the sample spectrum. CD spectra were recorded in milidegree (CD mdeg) and applied to calculate the secondary structure of the enzyme.

\section{Fermentation Kinetics Study}

For fermentation using agro-wastes by $A$. terreus, the logistic Equation 1 and Luedeking-Piret model (Equation 2) were employed for microbial growth and enzyme biosynthesis, respectively. It is as follows.

$$
\begin{aligned}
& d x / d t=\mu_{\max }\left\{1-\left(x / x_{\max }\right)\right\} x \\
& d P / d t=\alpha \mu x-\beta x
\end{aligned}
$$

Where, $d x / d t$ : biomass accumulation in the culture medium $(\mathrm{g} / \mathrm{L} / \mathrm{h}) ; d P / d t$ : enzyme accumulation in the culture medium $(\mathrm{U} / \mathrm{ml} / \mathrm{h}) ; x$ : biomass $(\mathrm{mg} / \mathrm{ml})$ at time $(\mathrm{t}) ; \mu$ : specific growth rate (h-1); $\mu_{\text {max }}$ : highest specific growth rate observed during batch culture $(\mathrm{mg} / \mathrm{L} / \mathrm{h}) ; x_{\text {max }}$ : maximum attainable biomass $(\mathrm{mg} / \mathrm{ml})$; $\alpha$ : growth associated coefficient of enzyme production $(\mathrm{U} / \mathrm{g}) ; \beta$ : growth-independent coefficient of enzyme production $(\mathrm{U} / \mathrm{g} / \mathrm{h})$.

\section{Statistical Analysis}

Every experiment was performed in triplicates $(n=3)$ and repeated thrice. The enzyme sample recovered after fermentation from each replicate was estimated for production of amylase, its activity and scale up of fermentation conditions. Each value presented is the mean of three parallel replicates. The \pm and error bars define standard deviation among the replicates. For result, one way ANOVA analysis was performed using SPSS 16.0 workbook software. Least significant differences were also evaluated by Duncan's new multiple range tests.

\section{RESULTS}

\section{Physical Properties and Physico-Chemical Parameters of Substrates}

For the present study, different substrates were selected. The physical and physico-chemical parameters of the substrates were analyzed. Pearl millet (Pennisetum typhoideum Rich. in Pers.; Family: Poaceae) was grayish to milky white in color after grinding to powder. Similarly, the finger millet (Eleusine coracana L. Gaertn.; Family: Poaceae) was creamy white in color after grinding. Mustard oil cake (Brassica campestris L.; Family: Cruciferae/Brassicaceae) was brown to olive brown in color. Fresh banana peels (Musa paradisiaca L.; Family: Musaceae) were initially yellow in color, but a significant darkening was observed on drying. There was a change in color varying from olive to olive brown when dried under shade. Dried chickling vetch (Lathyrus sativus L.; Family: Papilionaceae/Fabaceae) were muddy brown in color, but after grinding to fine powder the color became yellowish muddy brown in color. The powder of pearl millet, finger millet and chickling vetch became slurry when boiled with double distilled water (at 1:10 ratio, w/v). Table 1 summarizes the proximate composition of different agro-substrates used for this study.
TABLE 1 | Chemical composition of various agro-wastes selected for amylase production using fermentation.

\begin{tabular}{lccccc}
\hline Chemical composition & PM & FM & MoC & BP & CVP \\
\hline CONSTITUENTS (\% OF DRY MATTER) & & & & \\
Ash & 1.9 & 2.6 & $4.39-3.29$ & 8.98 & 1.95 \\
Moisture & $55 \%$ & $63 \%$ & $45 \%$ & $1.47(\mathrm{dry}) /$ & $59 \%$ \\
& & & & $82.6(\mathrm{fresh})$ & \\
Protein (mg/g) & 0.286 & 0.25 & 0.275 & 0.299 & 0.45 \\
Carbohydrate (mg/g) & 272.56 & 217.98 & 191.47 & 163.72 & 48.68 \\
Starch (mg/g) & 245.31 & 196.18 & 172.32 & 147.35 & 43.81 \\
Oil & - & - & 2.05 & - & - \\
Total nitrogen & - & - & $6.76-5.85$ & - & - \\
MINERAL (mg/100 g) & & & & & \\
Calcium & 37 & 34 & $0.3-0.5$ & 204.80 & 27 \\
HEAVY METALS (ppm/g) & & & & & \\
Chromium & 0.01 & 0.02 & 0.02 & 0.01 & 0.01 \\
Copper & 0.006 & 0.004 & 0.009 & 0.007 & 0.01 \\
Nickel & 0.001 & 0.002 & 0.001 & 0.002 & 0.001 \\
Lead & 0.001 & 0.001 & 0.004 & 0.003 & 0.003 \\
\hline (m) & & & & & \\
\hline
\end{tabular}

PM, pearl millet; FM, finger millet; MoC, mustard oil cake; BP, banana peels; CVP, Chickling vetch peels.

\section{Selection of Suitable Substrates for Production of $\alpha$-Amylase}

Process optimization and selection of suitable substrate (s) may involve the screening of several agro-industrial residues as substitutes of expensive substrates like pure starch. In an attempt to opt an impending and economic substrate for fermentation which would support optimum $\alpha$-amylase biosynthesis, various agro-residues like MoC, NoC, GnoC, BGP, GGP, CVP, WB, BR, $\mathrm{PM}, \mathrm{FM}, \mathrm{BP}, \mathrm{AP}$, and OP were used individually as the substrates for screening. Amongst the various substrates supplemented, pearl millet (PM) was found to be the most appropriate substrate for production of $\alpha$-amylase at LSSF and SSF $\left(1.69 \pm 0.22 \mathrm{Uml}^{-1}\right.$; $19.19 \pm 0.96 \mathrm{Ugds}^{-1}$; Table 2). Biosynthesis of this enzyme was also enhanced by FM, WB, RB and BR whereas AP, BP, OP, GGP, and BGP were comparatively not suitable for synthesis of $\alpha$-amylase (Table 2).

\section{Amendment of Culture Parameters and Fermentation Scale-up Effect of Initial Medium pH, Temperature, and Cultivation Time on Biosynthesis of $\alpha$-Amylase}

Maximum $\alpha$-amylase biosynthesis and excretion was attained at $\mathrm{pH} 7.0$ with biomass optima at $\mathrm{pH} 6.0$ (Figure 1A). However, the final $\mathrm{pH}$ of the fermentation medium was decreased in comparison to initial $\mathrm{pH}$ of the medium. Similarly, liquid static surface fermentation was performed with $1 \times 10^{7}$ spores $\mathrm{ml}^{-1}$ inoculum and incubated at varying temperature range of $24-45^{\circ} \mathrm{C}$ for $96 \mathrm{~h}$ to appraise the effect of incubating temperatures on growth and biosynthesis of $\alpha$-amylase. Maximum production of $\alpha$-amylase and biomass were observed in the temperature range of $27-36^{\circ} \mathrm{C}$ which indicated the mesophilic nature of $A$. terreus (Figure 1A). Increase in 
TABLE 2 | Enzyme biosynthesis by AspergillusterreusNCFT4269.10 in liquid static surface culture and solid state culture systems using various agricultural wastes as the substrates.

\begin{tabular}{|c|c|c|c|c|}
\hline $\begin{array}{l}\text { Fermentation } \\
\text { medium }\end{array}$ & $\begin{array}{l}\text { Cultivation } \\
\text { regimen }\end{array}$ & $\begin{array}{l}\text { Amylase } \\
\text { Activity }\end{array}$ & $\begin{array}{l}\text { Total } \\
\text { protein }\end{array}$ & $\begin{array}{l}\text { Biomass } \\
(\mathrm{g} / 50 \mathrm{ml})\end{array}$ \\
\hline \multirow[t]{2}{*}{$\mathrm{MoC}$} & LSSF & $1.697 \pm 0.27$ & $521.87 \pm 4.14$ & $0.203 \pm 0.013$ \\
\hline & SSF & $17.8 \pm 2.33$ & $7.928 \pm 1.90$ & - \\
\hline \multirow[t]{2}{*}{ NoC } & LSSF & $0.49 \pm 0.03$ & $859.99 \pm 1.21$ & $0.094 \pm 0.007$ \\
\hline & SSF & $1.17 \pm 0.61$ & $8.811 \pm 1.97$ & - \\
\hline \multirow[t]{2}{*}{ GnoC } & LSSF & $0.354 \pm 0.09$ & $393.88 \pm 1.58$ & $0.243 \pm 0.002$ \\
\hline & SSF & $2.11 \pm 0.62$ & $1.977 \pm 0.78$ & - \\
\hline \multirow[t]{2}{*}{ BGP } & LSSF & $0.599 \pm 0.34$ & $870.54 \pm 2.46$ & $0.085 \pm 0.002$ \\
\hline & SSF & $2.36 \pm 0.14$ & $6.539 \pm 1.58$ & - \\
\hline \multirow[t]{2}{*}{ GGP } & LSSF & $0.697 \pm 0.27$ & $579.99 \pm 2.22$ & $0.157 \pm 0.004$ \\
\hline & SSF & $7.44 \pm 0.95$ & $9.216 \pm 2.25$ & - \\
\hline \multirow[t]{2}{*}{ CVP } & LSSF & $1.414 \pm 0.234$ & $1133.66 \pm 7.89$ & $0.2108 \pm 0.006$ \\
\hline & SSF & $1.543 \pm 0.387$ & $12.89 \pm 2.32$ & - \\
\hline \multirow[t]{2}{*}{ WB } & LSSF & $0.564 \pm 0.07$ & $582.77 \pm 2.42$ & $0.080 \pm 0.001$ \\
\hline & SSF & $1.042 \pm 0.25$ & $3.133 \pm 1.02$ & - \\
\hline \multirow[t]{2}{*}{ PM } & LSSF & $1.697 \pm 0.22$ & $246.19 \pm 3.76$ & $0.1412 \pm 0.212$ \\
\hline & SSF & $19.19 \pm 0.96$ & $28.98 \pm 5.66$ & - \\
\hline \multirow[t]{2}{*}{ FM } & LSSF & $0.981 \pm 0.24$ & $540.55 \pm 2.35$ & $0.032 \pm 0.004$ \\
\hline & SSF & $7.44 \pm 0.93$ & $2.594 \pm 0.88$ & - \\
\hline \multirow[t]{2}{*}{$\mathrm{BR}$} & LSSF & $0.599 \pm 0.04$ & $259 \pm 0.073$ & $0.1981 \pm 0.0812$ \\
\hline & SSF & $2.36 \pm 0.36$ & $3.21 \pm 0.921$ & - \\
\hline \multirow[t]{2}{*}{ BP } & LSSF & $0.101 \pm 0.02$ & $153.32 \pm 4.26$ & $0.017 \pm 0.044$ \\
\hline & SSF & $1.94 \pm 0.33$ & $2.32 \pm 0.79$ & - \\
\hline \multirow[t]{2}{*}{ AP } & LSSF & $0.152 \pm 0.04$ & $177.33 \pm 1.211$ & $0.2117 \pm 0.0217$ \\
\hline & SSF & $1.74 \pm 0.61$ & $1.896 \pm 0.511$ & - \\
\hline \multirow[t]{2}{*}{ OP } & LSSF & $0.126 \pm 0.09$ & $891.65 \pm 2.66$ & $0.031 \pm 0.065$ \\
\hline & SSF & $0 \pm 0.00$ & $9.33 \pm 2.09$ & - \\
\hline CONTROL* & LSSF & $0.668 \pm 0.19$ & $211.66 \pm 2.88$ & $0.109 \pm 0.079$ \\
\hline
\end{tabular}

${ }^{*}$ Control refers to the basal medium with $1 \%(w / v)$ starch as inducer of amylase.

aThe liquid static surface fermentation (LSSF) and solid state fermentation (SSF) experiments were performed for $96 \mathrm{~h}$ at $30^{\circ} \mathrm{C}$. The data represent mean $\pm S D$ of replicates ( $n=3$ ). $\left\{\mathrm{Uml}^{-1}, \mu \mathrm{gml}^{-1}\right.$, and $\mu \mathrm{molml}^{-1}$ are used for LSSF; Ugds ${ }^{-1}, \mathrm{mggds}^{-1}$, and $\mu$ molgds ${ }^{-1}$ are used for SSF\}.

Weight of biomass (W3) = weight of biomass and filter paper (W1) - only weight of filter paper (W2)].

temperature retarded the production of $\alpha$-amylase and biomass, respectively.

Keeping the $\mathrm{pH}$ (7.0) constant, the cultivation period was standardized for synthesis of $\alpha$-amylase in fermentation medium by $A$. terreus. Production of $\alpha$-amylase commenced at $24 \mathrm{~h}$ and reached to maximum at $96 \mathrm{~h}$ but biomass was substantially increased up to $144 \mathrm{~h}$. The $\mathrm{pH}$ of the culture broth became slightly acidic (5.9-5.5) at $96 \mathrm{~h}$ when the synthesis of enzyme was the paramount. Further incubation after $96 \mathrm{~h}$ could not enhance enzyme activity, rather a gradual decrease was noticed (Figure 1B).

\section{Influence of Additional Carbon, Organic, and Inorganic Nitrogen Sources and Amino Acids on Production of $\alpha$-Amylase}

Biosynthesis of $\alpha$-amylase was carried out at specific $\mathrm{pH}$ and temperature for $96 \mathrm{~h}$ with additional supply of carbon sources.
It was concluded that supplementation of maltose supported enzyme synthesis. Rest carbon sources have no significant participation in $\alpha$-amylase production (Figure 1C). Similarly, different nitrogen sources were supplemented individually in LSSF at $1 \%(w / v)$ and appraised their aptness for the production of $\alpha$-amylase. Various proteins, ammonium and sodium salts were employed as nutritional additives. Figure $1 \mathrm{C}$ represents the variations in production of $\alpha$-amylase among the tested additives. Biosynthesis of $\alpha$-amylase was optimum with supplementation of gelatin as organic nitrogen source. However, various investigated inorganic nitrogen sources could not stimulate the highest biosynthesis of $\alpha$-amylase.

Amino acids and other trace nutrients are added as nitrogen supplements to complex media or have been used in combination with inorganic salts to improve the quality of media for higher enzyme activity. In the present study, 17 amino acids were supplemented to the fermentation medium independently and observed that the essential non-polar amino acid, isoleucine ( $1 \mathrm{mM}$ concentration) had only enhanced the $\alpha$-amylase activity up to two-fold. At the same time, maximum biomass was produced with the supplementation of the heterocyclic non-polar amino acid, tryptophan (Table 3).

\section{Effect of Metal lons, Vitamins, and Growth Regulators on Biosynthesis of $\alpha$-Amylase}

Several metal ions have been supplemented to the fermentation medium and observed that production of $\alpha$-amylase was enhanced by the supplementation of $\mathrm{Mg}^{2+}$ and $\mathrm{Ca}^{2+}$ (Table 3). Rest metal ions have not supported the enhanced biosynthesis of amylase. At all optimized conditions, the role of antioxidant vitamins (vitamin $\mathrm{C}$, riboflavin, folic acid and vitamin $\mathrm{E}$ at concentrations ranging from 10 to $50 \mathrm{mg} / 100 \mathrm{ml}$ ) on $\alpha$-amylase production was appraised by LSSF as it is unevaluated until now using A. terreus NCFT 4269.10. From this study, it was concluded that vitamin $\mathrm{E}$ at $30 \mathrm{mg} / 100 \mathrm{ml}$ concentration exhibited maximum $\alpha$-amylase biosynthesis $(101.2 \pm 10.7 \mathrm{Uml}-$ 1) as well as generation of biomass (Table 3). About 60 -fold increases in $\alpha$-amylase activity was attained with the fat soluble vitamin E (30 mg/100 ml; Table 3).

A. terreus NCFT 4269.10 was inoculated to pearl millet medium (LSSF) supplemented with different growth regulators like, gibberellic acid, kinetin, 6-benzylaminopurine (BAP), and 2, 4-dichlorophenoxyacetic acid (2,4-D) at the concentration of $0.025 \%(w / w)$ after sterilization and allowed to cool down. In this study, gibberellic acid followed by kinetin had only positive influence on production of $\alpha$-amylase (Table 3 ).

\section{Role of Combined Agro-Wastes, Inoculum Size, and Moisture Content on $\alpha$-Amylase Production}

Combinations of different substrates and its synergistic effect on biosynthesis of $\alpha$-amylase were evaluated using pearl millet (PM), finger millet (FM) and oat. It was observed that PM: Oat at a ratio of 7:3 $\left(30.98 \pm 0.72 \mathrm{Uml}^{-1}\right)$ and $\mathrm{FM}$ : Oat at a ratio of 7:3 $\left(30.84 \pm 11.01 \mathrm{Uml}^{-1}\right)$ exhibited maximum production of $\alpha$-amylase by $A$. terreus. Most of these combinations exhibited significant production as compared to the control (Table 4). 


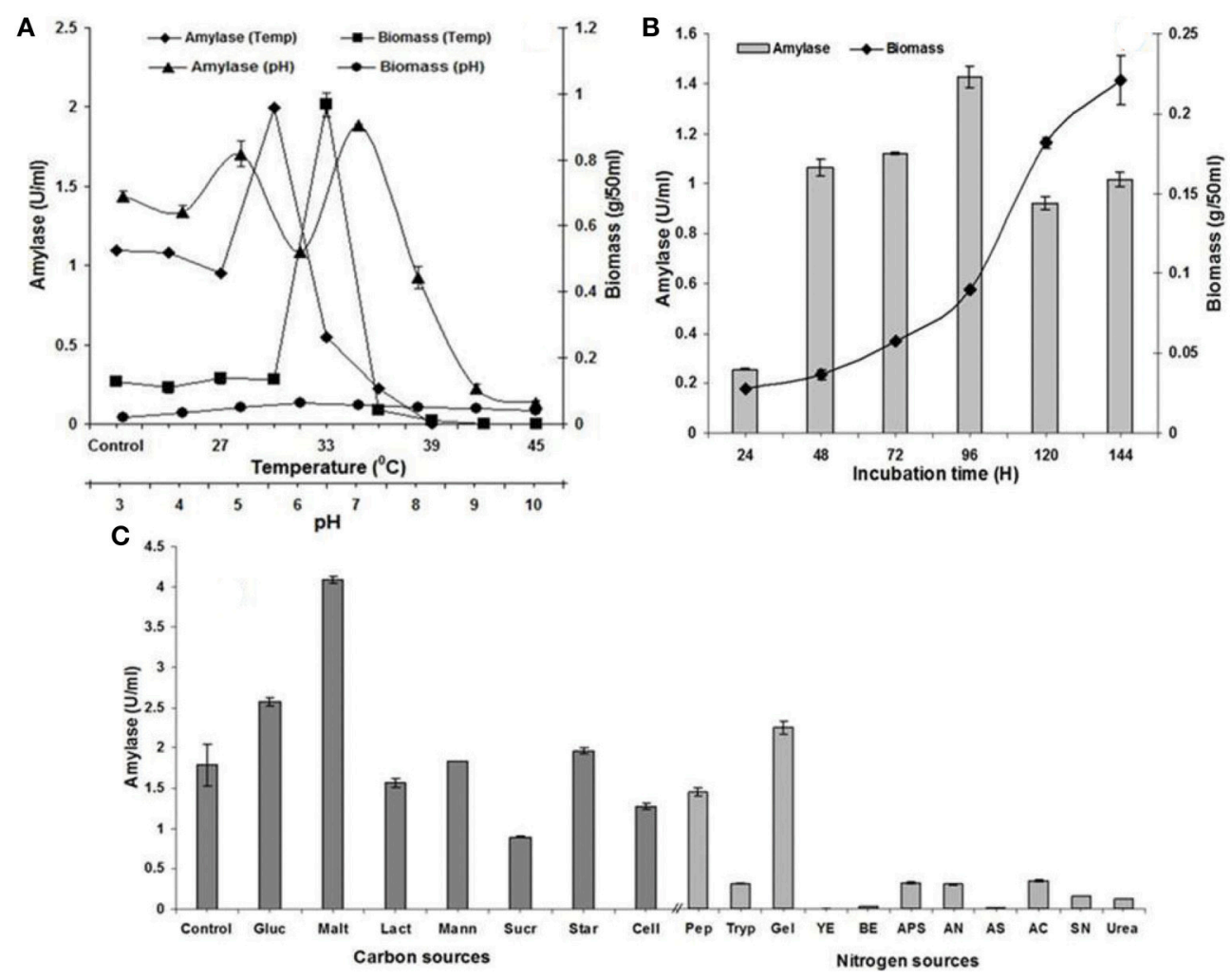

FIGURE 1 | (A) Effect of $\mathrm{pH}(3.0-10.0)$ and temperature $\left(24-45^{\circ} \mathrm{C}\right.$ at $3^{\circ} \mathrm{C}$ interval) on amylase production and mycelia growth in liquid static surface culture (LSSF) by A. terreus NCFT 4269.10 after $96 \mathrm{~h}$ of cultivation; (B) Influence of incubation time on amylase production and mycelia growth during liquid static surface culture by $A$. terreus NCFT 4269.10 using Pearl millet added fermentation medium; (C) Effect of various carbon and nitrogen sources on the mycelia growth and amylase production by A. terreus, where, Gluc, Glucose; Malt, Maltose; Lact, Lactose; Mann, Mannose; Sucr, Sucrose; Star, Starch; Cell, Cellulose; Pep, peptone; Tryp, tryptone; Gel, Gelatin; YE, Yeast extract; BE, Beef extract; APS, Ammonium persulphate; AN, Ammonium nitrate; AS, Ammonium sulfate; AC, Ammonium chloride; SN, Sodium nitrate.

Meanwhile, inoculum concentrations of A. terreus NCFT 4269.10 varying from 2 to $10 \%(\mathrm{v} / \mathrm{w})$ were employed by spore counting with haemocytometer and spectrophotometric analysis. Rate of enzyme production increased with rise in inoculum size and exhibited maximum synthesis of enzyme at $96 \mathrm{~h}$ with $4 \%$ $(\mathrm{v} / \mathrm{w})$ inoculum concentration with a gradual decline thereafter (Figure 2). As compared to control, it was observed that there was a significant effect of size of spore inoculum on amylolytic activity.

The percentage of moisture content also varied according to the water holding potentiality of the substrates. Therefore, water holding capacity of PM had been examined and required amount of sterilized double distilled water was added to the substrate to adjust the moisture content in between 20 and 100\%. The optimum $\alpha$-amylase production was observed at $70 \%$ of moisture content, which indicated that the water holding ability of PM was poor (Figure 2).

\section{Downstream Processing}

For development of an efficient recovery protocol, the fermented matter was soaked with phosphate buffer, $\mathrm{pH} 6.5(0.1 \mathrm{M})$ at different time interval to establish a suitable soaking time period for maximum recovery of the enzyme. It was concluded that $1 \mathrm{~h}$ of soaking was most suitable in release of $\alpha$-amylase, whereas, further incubation with phosphate buffer decreased the enzyme recovery (Table 5). When repeated extraction was performed for $\alpha$-amylase, second extraction exhibited significant amylolytic activity i.e., $3.16 \pm 0.02 \mathrm{Uml}^{-1}$. Among different extractants, $\mathrm{PB}$ along with Urea $(1 \mathrm{M})$ was most compatible for recovery of $\alpha$-amylase. When different extractants were used for recovery of $\alpha$-amylase, milliQ distilled water was found suitable for the efficient extraction of $\alpha$-amylase. Czapek Dox solution, distilled water, and ammonium sulfate $(1 \mathrm{M})$ could not permit the liberation of entrapped enzyme (Table 5).

\section{Purification of $\alpha$-Amylase, SDS-PAGE and Zymographic Analysis}

The cell-free dialyzed $\alpha$-amylase displayed $381 \mathrm{U}$ and 15.24 $\mathrm{Umg}^{-1}$ protein specific activity, $36.95 \%$ yield and 2.305 -fold purification. The dialized $\alpha$-amylase was further purified by a column of Sephadex G100 (Table 6) and purified to a homogeneity with 9.28 -fold, $27.35 \%$ yield, and a specific activity of $61.3 \mathrm{Umg}^{-1}$ using ammonium sulfate precipitation followed by Sephadex G-100 gel filtration chromatography giving one 
TABLE 3 | Effect of amino acids, metal ions, vitamins and growth regulators on amylase production by $A$. terreus NCFT $4269.10^{\mathrm{a}}$.

\begin{tabular}{|c|c|c|c|}
\hline \multirow[t]{2}{*}{ Different sources } & \multicolumn{3}{|c|}{ Amylase } \\
\hline & Biomass (g/50 ml) & Activity (U/ml) & Final $\mathrm{pH}^{\star}$ \\
\hline \multicolumn{4}{|c|}{ AMINO ACIDS (5 mM/100 ml) } \\
\hline Alanine & $0.10 \pm 0.005 c$ & $1.27 \pm 0.02 c$ & 4.6 \\
\hline Proline & $0.09 \pm 0.045 d$ & $2.53 \pm 0.008 a b$ & 6.0 \\
\hline Valine & $0.08 \pm 0.004 \mathrm{de}$ & $0 \pm 0.00$ & 4.3 \\
\hline Aspartic acid & $0.09 \pm 0.002 d$ & $0.8 \pm 0.01 d$ & 4.2 \\
\hline Methionine & $0.05 \pm 0.025 f$ & $1.28 \pm 0.02 \mathrm{c}$ & 5.0 \\
\hline Glutamate & $0.07 \pm 0.009 e$ & $2.65 \pm 0.17 a b$ & 4.5 \\
\hline L-lysine & $0.10 \pm 0.008 c$ & $0 \pm 0.00$ & 4.5 \\
\hline Cysteine & $0.09 \pm 0.044 d$ & $2.07 \pm 0.04 b$ & 4.3 \\
\hline Histidine & $0.09 \pm 0.018 d$ & $2.49 \pm 0.06 b$ & 4.1 \\
\hline Phenyl alanine & $0.07 \pm 0.024 d$ & $0.75 \pm 0.01 d$ & 4.4 \\
\hline Isolucine & $0.07 \pm 0.003 e$ & $3.81 \pm 0.009 a$ & 4.0 \\
\hline Threonine & $0.06 \pm 0.004 \mathrm{ef}$ & $3.07 \pm 0.02 a b$ & 5.0 \\
\hline Tryptophan & $0.12 \pm 0.016 c$ & $1.26 \pm 0.003 c$ & 4.7 \\
\hline Agrinine & $0.05 \pm 0.001 f$ & $0 \pm 0.00$ & 3.8 \\
\hline Leucine & $0.01 \pm 0.001 i$ & $2.60 \pm 0.09 b$ & 4.0 \\
\hline Glycine & $0.04 \pm 0.016 \mathrm{~g}$ & $2.04 \pm 0.02 b$ & 5.4 \\
\hline Serine & $0.07 \pm 0.003 e$ & $0 \pm 0.00$ & 5.2 \\
\hline \multicolumn{4}{|c|}{ METAL IONS (1 mM) } \\
\hline $\mathrm{Zn}++$ & $0.68 \pm 0.013 a$ & $0.65 \pm 0.062 d$ & 4.3 \\
\hline $\mathrm{K}^{+}$ & $0.72 \pm 0.085 a$ & $0.92 \pm 0.015 \mathrm{~cd}$ & 3.7 \\
\hline $\mathrm{Ag}^{++}$ & $0.05 \pm 0.014 f$ & $0.81 \pm 0.051 \mathrm{~cd}$ & 4.4 \\
\hline $\mathrm{Fe}^{++}$ & $0.58 \pm 0.004 b$ & $0.42 \pm 0.006 e$ & 3.4 \\
\hline $\mathrm{Mg}^{++}$ & $0.68 \pm 0.141 \mathrm{ab}$ & $2.33 \pm 0.145 b$ & 4.4 \\
\hline $\mathrm{Cu}^{++}$ & $0.02 \pm 0.001 \mathrm{~h}$ & $0.55 \pm 0.004 e$ & 3.7 \\
\hline $\mathrm{Mn}^{+}$ & $0.01 \pm 0.000 i$ & $0.93 \pm 0.022 d$ & 8.6 \\
\hline $\mathrm{Ca}^{+}$ & $0.70 \pm 0.170 a$ & $1.94 \pm 0.041 c$ & 4.2 \\
\hline $\mathrm{Hg}^{++}$ & $0.02 \pm 0.003 \mathrm{~h}$ & $0.52 \pm 0.022 e$ & 4.0 \\
\hline EDTA & $0.03 \pm 0.000 \mathrm{~g}$ & $0.76 \pm 0.004 d$ & 5.4 \\
\hline \multicolumn{4}{|c|}{ VITAMINS (mg/100 ml) } \\
\hline \multicolumn{4}{|l|}{ Vitamin C } \\
\hline 10 & $0.38 \pm 0.10 \mathrm{e}$ & $19.7 \pm 0.7 e$ & 6.9 \\
\hline 20 & $0.12 \pm 0.00 \mathrm{~g}$ & $4.8 \pm 1.3 f$ & 6.4 \\
\hline 30 & $0.73 \pm 0.09 b$ & $54.1 \pm 4.9 c$ & 6.1 \\
\hline 40 & $0.43 \pm 0.01 \mathrm{de}$ & $25.1 \pm 0.6 d$ & 6.4 \\
\hline 50 & $0.2 \pm 0.00 f$ & $4.9 \pm 1.7 f$ & 6.5 \\
\hline \multicolumn{4}{|l|}{ Riboflavin } \\
\hline 10 & $0.57 \pm 0.00 \mathrm{~cd}$ & $33.1 \pm 3.7 d$ & 6.2 \\
\hline 20 & $0.14 \pm 0.00 \mathrm{~g}$ & $2.1 \pm 3.0 \mathrm{~g}$ & 6.6 \\
\hline 30 & $0.66 \pm 0.08 \mathrm{~cd}$ & $58.8 \pm 2.2 c$ & 6.6 \\
\hline 40 & $0.73 \pm 0.06 b$ & $92.3 \pm 1.3 b$ & 6.7 \\
\hline 50 & $0.09 \pm 0.00 \mathrm{~h}$ & $2.2 \pm 0.6 \mathrm{~g}$ & 6.2 \\
\hline \multicolumn{4}{|l|}{ Folic acid } \\
\hline 10 & $0.08 \pm 0.00 h$ & $0.3 \pm 0.4 i$ & 5.2 \\
\hline 20 & $0.07 \pm 0.00 \mathrm{~h}$ & $0.6 \pm 0.4 h$ & 5.1 \\
\hline 30 & $0.04 \pm 0.00 \mathrm{i}$ & $0 \pm 0.0$ & 5.4 \\
\hline 40 & $0.11 \pm 0.00 \mathrm{~g}$ & $6.7 \pm 0.4 f$ & 5.3 \\
\hline 50 & $0.43 \pm 0.07 d$ & $22.1 \pm 1.9 \mathrm{de}$ & 5.5 \\
\hline
\end{tabular}

(Continued)
TABLE 3 | Continued

Different sources

Amylase

Biomass (g/50 ml) Activity (U/ml) Final pH*

Vitamin E

$\begin{array}{lccc}10 & 0.08 \pm 0.00 \mathrm{gh} & 0.9 \pm 0.4 \mathrm{~h} & 6.3 \\ 20 & 0.06 \pm 0.00 \mathrm{hi} & 0.3 \pm 0.4 \mathrm{i} & 6.2 \\ 30 & 0.85 \pm 0.06 \mathrm{a} & 101.2 \pm 10.7 \mathrm{a} & 5.7 \\ 40 & 0.45 \pm 0.00 \mathrm{~d} & 39.5 \pm 0.2 \mathrm{~d} & 6.3 \\ 50 & 0.43 \pm 0.01 \mathrm{~d} & 41.2 \pm 22.3 \mathrm{~cd} & 6.4 \\ \text { GROWTH REGULATORS (0.0025 } \mathbf{~} \mathbf{g} / \mathbf{g}, \mathbf{w} / \mathbf{w}) & & \\ \text { Gibberellic acid } & 0.12 \pm 0.02 \mathrm{a} & 2.03 \pm 0.07 \mathrm{a} & 5.2 \\ \text { Kinetin } & 0.05 \pm 0.02 \mathrm{c} & 0.24 \pm 0.00 \mathrm{~cd} & 4.7 \\ \text { 6-Benzylaminopurine } & 0.07 \pm 0.02 \mathrm{bc} & 0.60 \pm 0.03 \mathrm{~b} & 4.9 \\ \text { 2,4-Dichlorophenoxyacetic } & 0.05 \pm 0.01 \mathrm{c} & 0.47 \pm 0.0 \mathrm{~d} & 5.3\end{array}$

acid

a The liquid static surface culture experiments were performed for 4 days at $30^{\circ} \mathrm{C}$ for all the cases using PM as the substrate.

$\mathrm{pH}^{*}$, Initial $\mathrm{pH}$ was adjusted 7.0 required for the biosynthesis of amylase.

${ }^{*}$ Control refers to the PM added fermentation broth medium (10\% w/V) devoid of amino acids, metal ions, vitamins and growth regulators. The data represent mean $\pm S D$ of replicates $(n=3)$. Mean values within a column with different letters are significantly different at $p \leq 0.05$.

TABLE 4 | Effect of mixed agro-wastes on amylase biosynthesis.

\begin{tabular}{lcc}
\hline Mixed substrates & Ratio & Enzyme activity (Ugds ${ }^{-1}$ ) \\
\hline & $1: 9$ & $30.21 \pm 0.36 \mathrm{a}$ \\
Pearl millet: oat & $3: 7$ & $15.99 \pm 2.50 \mathrm{~cd}$ \\
& $5: 5$ & $29.71 \pm 1.79 \mathrm{~b}$ \\
& $7: 3$ & $30.98 \pm 0.72 \mathrm{a}$ \\
Pearl millet: finger millet & $9: 1$ & $10.16 \pm 2.15 \mathrm{e}$ \\
& $1: 9$ & $7.871 \pm 3.22 \mathrm{f}$ \\
& $3: 7$ & $6.65 \pm 0.06 \mathrm{~g}$ \\
Finger millet:oat & $5: 5$ & $15.41 \pm 0.46 \mathrm{c}$ \\
& $7: 3$ & $12.23 \pm 0.05 \mathrm{~d}$ \\
& $9: 1$ & $15.41 \pm 0.23 \mathrm{c}$ \\
Control & $1: 9$ & $3.05 \pm 0.71 \mathrm{~h}$ \\
& $3: 7$ & $3.65 \pm 0.09 \mathrm{~h}$ \\
& $5: 5$ & $19.11 \pm 1.17 \mathrm{bc}$ \\
& $7: 3$ & $30.84 \pm 1.01 \mathrm{a}$ \\
& $9: 1$ & $18.05 \pm 0.32 \mathrm{bc}$ \\
& & $19.30 \pm 0.32 \mathrm{bc}$ \\
& & \\
& &
\end{tabular}

${ }^{*}$ Control refers to only PM taken as solid state fermentation medium (10\% w/V). The solid state fermentation setups were performed as per the above combination for a period of $96 \mathrm{~h}$ at $30^{\circ} \mathrm{C}$. The data represent mean $\pm S D$ of replicates $(n=3)$. Mean values within a column with different letters are significantly different at $p \leq 0.05$.

peak. The specific activity of $\alpha$-amylase was increased from 6.6 to $61.30 \mathrm{Umg}^{-1}$ (10-fold) after purification.

Before and after purification, the crude and purified $\alpha$-amylase was analyzed by SDS-PAGE. Gel images of both purified enzyme and zymogram confirmed that various undesired proteins were eluted out during the series of purification. The crude supernatants of fermented sample of both LSSF and SSF were found to be rich in different types of proteins and exhibited 8 


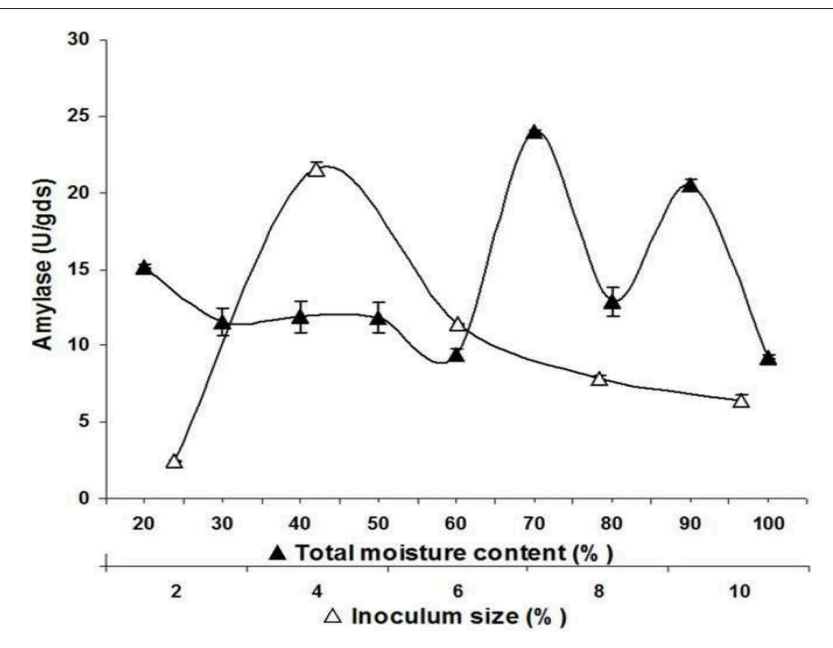

FIGURE 2 | Effect of initial moisture content and inoculum size on biosynthesis of extracellular amylase by $A$. terreus NCFT 4269.10 performed for $96 \mathrm{~h}$ at $30^{\circ} \mathrm{C}$ using solid state fermentation.

bands. The banding patterns were unique representing diversity in gene expression. The bands of the crude extracts of $\alpha$ amylase were found to be in a range of $7-175 \mathrm{kDa}$ (Figure 3A). However, the molecular weight of purified $\alpha$-amylase was 15.3 $\mathrm{kDa}$ (Figure 3B). When zymograms were prepared, $\alpha$-amylase exhibited a single clear hydrolyzed band (Figure 3C). It was possible to verify the presence of eight bands with/without amylolytic activities revealed by $\mathrm{KI}$ and $\mathrm{I}_{2}$ solutions by measuring the loss of binding capacity between starch and iodine resulting from the action of $\alpha$-amylases and concluded a single band showing the activity (Figure 3C).

\section{Circular Dichroism (CD) Spectroscopic Analysis}

The secondary structure composition of $A$. terreus NCFT 4269.10 $\alpha$-amylase was evaluated by CD spectra (Figure 4). The isolated $\alpha$-amylase was found to have $12.2 \% \alpha$-helix, $23.6 \%$ parallel $\beta$-sheet, $27.4 \% \beta$-turn, and $36.8 \%$ random coil (Figure 4).

\section{Fermentation Kinetics Study}

The kinetic evaluation results also revealed that the optimum fermentation period for extracellular biosynthesis of $\alpha$-amylase by $A$. terreus was $96 \mathrm{~h}$ with a constant growth rate. Nonetheless, growth and enzyme secretion were significantly affected by engineering of the fermentation media (supplementation of nutrients) and optimization of different parameter. The specific production rate and growth coefficient favored hyper production of extracellular $\alpha$-amylase (Table 7).

\section{DISCUSSION}

For production of enzymes and secondary metabolites, fungi represent huge groups of filamentous saprophytic organisms with a remarkable genetic repertoire. But, amongst
TABLE 5 | Effect of soaking time, repeated extraction and various extractants on amylase recovery.

\begin{tabular}{|c|c|c|c|}
\hline \multirow[t]{2}{*}{ Extraction } & \multicolumn{3}{|c|}{ Amylase activity } \\
\hline & Ugds $^{-1}$ & $\mathrm{Umg}^{-1}$ & $\mathrm{Ug}^{-1}$ \\
\hline \multicolumn{4}{|l|}{ SOAKING TIME } \\
\hline 0.5 & $10.91 \pm 0.33 f$ & $9.41 \pm 1.14 f$ & $2.18 \pm 0.41 f$ \\
\hline 1 & $18.04 \pm 1.84 d$ & $8.39 \pm 1.22 f$ & $3.57 \pm 0.16 d$ \\
\hline 3 & $8.34 \pm 0.27 \mathrm{gh}$ & $5.29 \pm 1.43 h$ & $1.66 \pm 0.15 g$ \\
\hline 5 & $4.55 \pm 0.64 i$ & $2.99 \pm 0.97 \mathrm{jk}$ & $0.90 \pm 0.03 h$ \\
\hline 7 & $14.61 \pm 2.21 e$ & $12.08 \pm 3.14 d$ & $2.91 \pm 0.04 \mathrm{ef}$ \\
\hline 17 & $13.82 \pm 1.13 \mathrm{e}$ & $12.88 \pm 3.13 d$ & $2.75 \pm 0.02 e$ \\
\hline 24 & $3.21 \pm 0.14 j$ & $2.98 \pm 0.71 \mathrm{jk}$ & $0.64 \pm 0.03 i$ \\
\hline 48 & $13.71 \pm 0.00 \mathrm{e}$ & $10.27 \pm 1.72 \mathrm{e}$ & $2.73 \pm 0.04 \mathrm{e}$ \\
\hline 72 & $3.42 \pm 0.55 \mathrm{k}$ & $3.03 \pm 0.40 h$ & $0.68 \pm 0.10 \mathrm{i}$ \\
\hline 96 & $14.75 \pm 0.00 e$ & $13.25 \pm 1.91 \mathrm{c}$ & $2.93 \pm 0.01 e$ \\
\hline \multicolumn{4}{|l|}{ REPEATED EXTRACTION } \\
\hline 1 & $18.22 \pm 1.53 d$ & $12.23 \pm 1.98 d$ & $3.63 \pm 0.73 d$ \\
\hline 2 & $31.64 \pm 5.21 b$ & $14.03 \pm 2.21 b c$ & $6.32 \pm 0.94 b$ \\
\hline 3 & $22.71 \pm 4.04 \mathrm{c}$ & $15.29 \pm 2.07 b$ & $4.54 \pm 0.91 c$ \\
\hline \multicolumn{4}{|c|}{ DIFFERENT EXTRACTANTS } \\
\hline PB (0.1M) & $1.63 \pm 0.18 \mathrm{~lm}$ & $2.24 \pm 0.13 \mathrm{jk}$ & $0.32 \pm 0.02 \mathrm{k}$ \\
\hline PB +Trit $\times 100(0.1 \%, w / v)$ & $1.65 \pm 0.241 \mathrm{~m}$ & ND & $0.329 \pm 0.03 \mathrm{k}$ \\
\hline PB + Trit $\times 100(0.5 \%, w / v)$ & $5.23 \pm 0.91 i$ & $2.54 \pm 0.13 k$ & $1.03 \pm 0.03 g$ \\
\hline PB + Trit $\times 100(1 \%, w / v)$ & $7.81 \pm 1.02 \mathrm{~h}$ & $3.74 \pm 0.26 i$ & $1.55 \pm 0.02 \mathrm{gh}$ \\
\hline PB + Urea (1M) & $21.02 \pm 3.04 \mathrm{~cd}$ & $7.68 \pm 0.92 \mathrm{fg}$ & $4.20 \pm 0.08 c$ \\
\hline PB+ Amm. Sulfate 1M & $15.71 \pm 1.21 \mathrm{e}$ & $6.60 \pm 0.91 \mathrm{~g}$ & $3.15 \pm 0.43 \mathrm{de}$ \\
\hline $\mathrm{NaCl}(0.5 \%)$ & $1.31 \pm 0.221$ & ND & $0.26 \pm 0.041$ \\
\hline DW & $41.15 \pm 3.12 \mathrm{a}$ & $31.79 \pm 3.58 a$ & $8.30 \pm 0.25 a$ \\
\hline CzapekDox & $2.63 \pm 0.001$ & $3.40 \pm 0.65 i$ & $0.51 \pm 0.09 i j$ \\
\hline
\end{tabular}

The solid state fermentation setups were performed for a period of $96 \mathrm{~h}$ at $30^{\circ} \mathrm{C}$. ND: not determined. The data represent mean $\pm S D$ of replicates $(n=3)$. Mean values within a column with different letters are significantly different at $p \leq 0.05$.

all filamentous fungi, Aspergillus is the most prevailing soildwelling amylolytic genus of the nature (Norouzian et al., 2006). Agricultural wastes are being exploited for both surface static liquid/ liquid shaking and solid state/substrate fermentation to lessen the final cost of fermentation media and to achieve the desired product. For economic biosynthesis of amylase using SSF and SmF from mycelial fungi, cereals bran and flour, potato waste and other starchy-component wastes have gained amazing importance in fermentation industries. Keeping in view, various agro-wastes were tried and evaluated for the high-valued-high volume enzyme biosynthesis for industrial applications focusing on the betterment of human kind. The substrate composition was analyzed carefully to obtain necessary information before fermentation. Therefore, various substrates were collected from different parts of Odisha, India and analyzed for physical and physico-chemical parameters. The pearl millet was found to be rich with starch content and available in ample quantities in Odisha, India. Other substrates, like, MoC, BP, and CVP are also rich sources of carbon and nitrogen and other macro and micronutrients required for the growth of the microorganisms. 
TABLE 6 | Purification summary of isolated amylase.

\begin{tabular}{|c|c|c|c|c|c|c|c|}
\hline Steps & Volume & $\begin{array}{l}\text { Activity } \\
\left(\mathrm{Uml}^{-1}\right)\end{array}$ & $\begin{array}{c}\text { Total enzyme } \\
\text { activity (U) }\end{array}$ & $\begin{array}{c}\text { Total } \\
\text { protein }(\mathrm{mg})\end{array}$ & $\begin{array}{c}\text { Specific } \\
\text { activity }\left(\mathrm{Umg}^{-1}\right)\end{array}$ & $\begin{array}{l}\text { Purification } \\
\text { fold }\end{array}$ & Yield (\%) \\
\hline Crude & 540 & 1.91 & 1031 & 155.99 & 6.6089 & 1.0 & 100 \\
\hline Ammonium sulphate precipitation & 15 & 25.4 & 381 & 25.0 & 15.24 & 2.305 & 36.95 \\
\hline Sephadex G-100 & 5 & 56.4 & 282 & 4.6 & 61.304 & 9.276 & 27.35 \\
\hline
\end{tabular}

The agricultural wastes are rich source of carbon and nitrogen that are indispensable for the growth and metabolism of microorganisms.

Generally, employment of starch as a constituent of fermentation medium for $\alpha$-amylase production is too expensive and can be replaced with zero-cost substrates otherwise regarded as the wastes. Therefore, the native isolate of $A$. terreus NCFT4269.10 was cultured in liquid medium using starch $(1.0 \%, w / w)$ and treated as control. At the same time, different agricultural based byproducts like, MoC, GnoC, NoC, BGP, GGP, WB, BP, OP, PM, and FM were taken for the study to find out the most suitable substrate for production of amylase. Amongst all, PM was found to be the most suitable substrate for production of amylase. Similarly, Khan and Yadav (2011) had also worked with Aspergillus niger supplementing various substrates (vegetable waste, rice husk and banana peels) for the production of $\alpha$-amylase. Aspergillus awamori nakazawa was also reported as an effective producer of glucoamylases and proteases in solid state fermentation with wheat bran as substrate (Negi and Banerjee, 2009). Acourene and Ammouche (2012) have produced $\alpha$-amylase using three fungal strains, Saccharomyces cerevisiae, A. niger, and Candida guilliermondii from date wastes. Roses and Guerra (2009) have optimized production of amylase by A. niger using sugarcane bagasse as the substrate by solid-state fermentation. At contemporary, much interest has been focused toward effective employment of different agro-industrial wastes, like, wheat bran, sugarcane bagasse, rye straw, wheat straw, oil cakes, corncob leaf, and many other residues for biosynthesis of amylases (Bhargav et al., 2008).

For growth of microorganism and production of different metabolites, $\mathrm{pH}$ of the fermentation medium, temperature and cultivation time plays an imperative role. In the present study, the production of amylase was significantly affected by varying $\mathrm{pH}$ of the fermentation medium. Alva et al. (2007) reported that pH 5.8 was most compatible for the $\alpha$-amylase production by Aspergillus sp. JGI12 which differ from the amylase produced by A. terreus. Enzyme secretion by microbial strains strongly depends on the extracellular $\mathrm{pH}$ as $\mathrm{pH}$ of the culture medium strongly influences many enzymatic reactions. As per the report of Zeni et al. (2011), the fall or rise of $\mathrm{pH}$ of fermentation medium due to metabolic activity of microorganism affects the utilization of nitrogen compounds and influences the biosynthesis of amylase directly or indirectly.

With connection to the present finding for the effect of temperature on production of amylase, similar result was reported by Alva et al. (2007) with Aspergillus sp. JGI 12 amylase. Nwagu and Okoli (2011) also observed that a particular strain of Aspergillus fumigatus exhibited maximum mycelial yield and amylase titre at $30^{\circ} \mathrm{C}$ which is akin to the present findings (Figure 1A), however, the reports of Negi and Banerjee (2010) on A. awamori for production of amylase was not at par with the present finding. As compared to the present study conducted for effect of cultivation time on production of amylase, similar result was reported by Negi and Banerjee (2010) for amylase biosynthesis using A. awamori. Mohamed et al. (2011) reported $96 \mathrm{~h}$ and $30^{\circ} \mathrm{C}$ for biosynthesis of amylase which is in accordance with present finding. However, Han et al. (2013) have reported a multifunctional $\alpha$-amylase from Malbranchea cinnamomea on the fifth day when wheat bran, rice bran and glutinous rice flour were employed as the carbon source under the optimized conditions. These reports however, differ from the present findings might be owing to the independent nature of the microorganisms.

Many researchers have also evaluated the effect of various additional carbon supplementations along with the regular substrates for enzyme production. Somehow, Negi and Banerjee (2010) have studied the influence of supplementary carbon sources for amylase biosynthesis and concluded that starch displayed enhanced production of amylase. This is not at par with the present findings. In this study, supplementation of additional carbon sources did not support the enhanced production of amylase. It may be due to the catabolite repression that usually imperatively affects the gene expression for the biosynthesis of $\alpha$-amylase. Monga et al. (2011) have also reported the use of casein and peptone for the biosynthesis of amylase using various Aspergillus species. Acourene and Ammouche (2012) reported that urea was the most compatible elicitor for biosynthesis of amylase from $A$. niger which disagrees with the present findings.

In addition to physical and nutritional parameters, metal ions, vitamins and growth regulators also have significant contribution in enhancing the biosynthesis and activity of enzymes as many of them also acts as co-factors or as modulators. In both the above cases, there was no obvious effect of metal ions on the mycelial growth because free $\mathrm{Ca}^{2+}$ and $\mathrm{Mg}^{2+}$ ion concentration controls exocytosis of eukaryotic proteins through "regulated secretion" pathways (Hoshino et al., 1991). The transition metal ions such as $\mathrm{Fe}^{3+}, \mathrm{Cu}^{2+}, \mathrm{Mn}^{2+}$, and $\mathrm{Zn}^{2+}$ intermingle with the surface charge of enzyme and also affect the ionization of some amino acid residues. Thus, finally alters the structural conformations of enzyme and render it as unstable and/or decreased activity which is referred as toxicity of ions (Glusker et al., 1999). This hypothesis was at par with the present findings for biosynthesis of $\alpha$-amylase by $A$. terreus. Similarly, as reported by Afifi et al. (2008) the water soluble vitamin C (tocopherols) was 


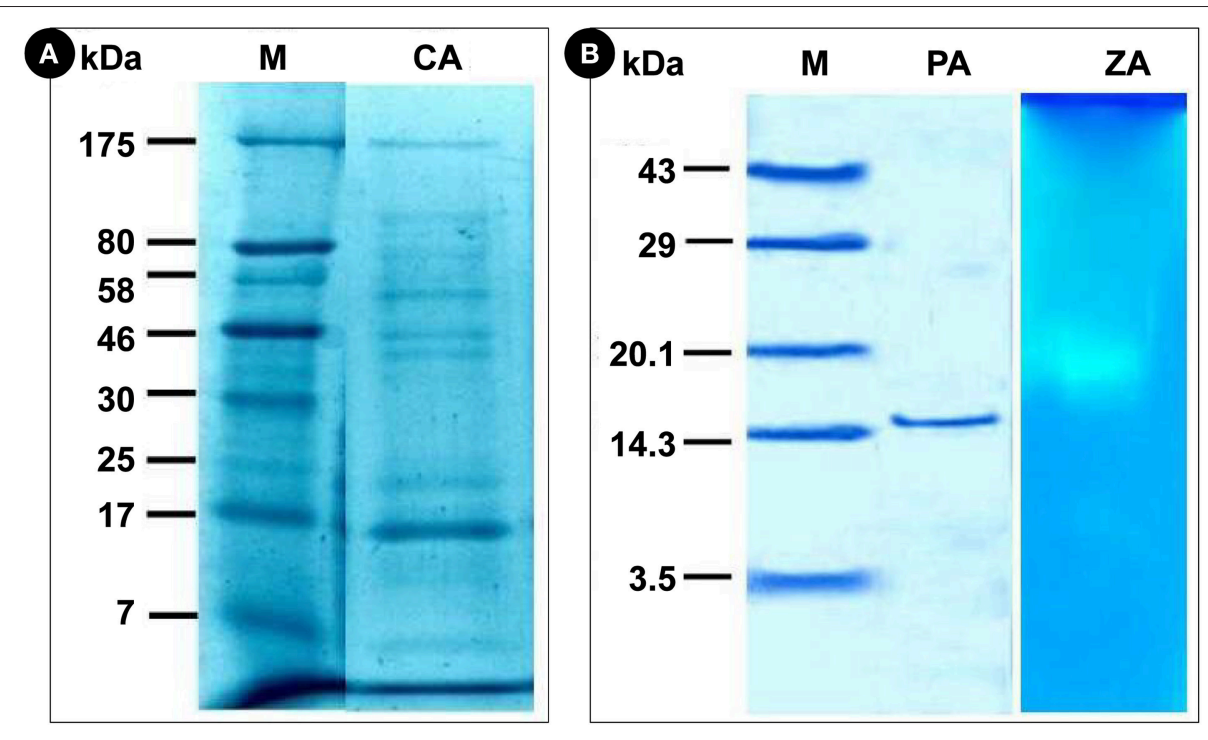

FIGURE 3 | Electrophoretic analysis of amylase. (A), M, Marker; CA, Crude amylase; (B), M, Marker; PA, Purified amylase; ZA, Zymographic analysis of amylase.

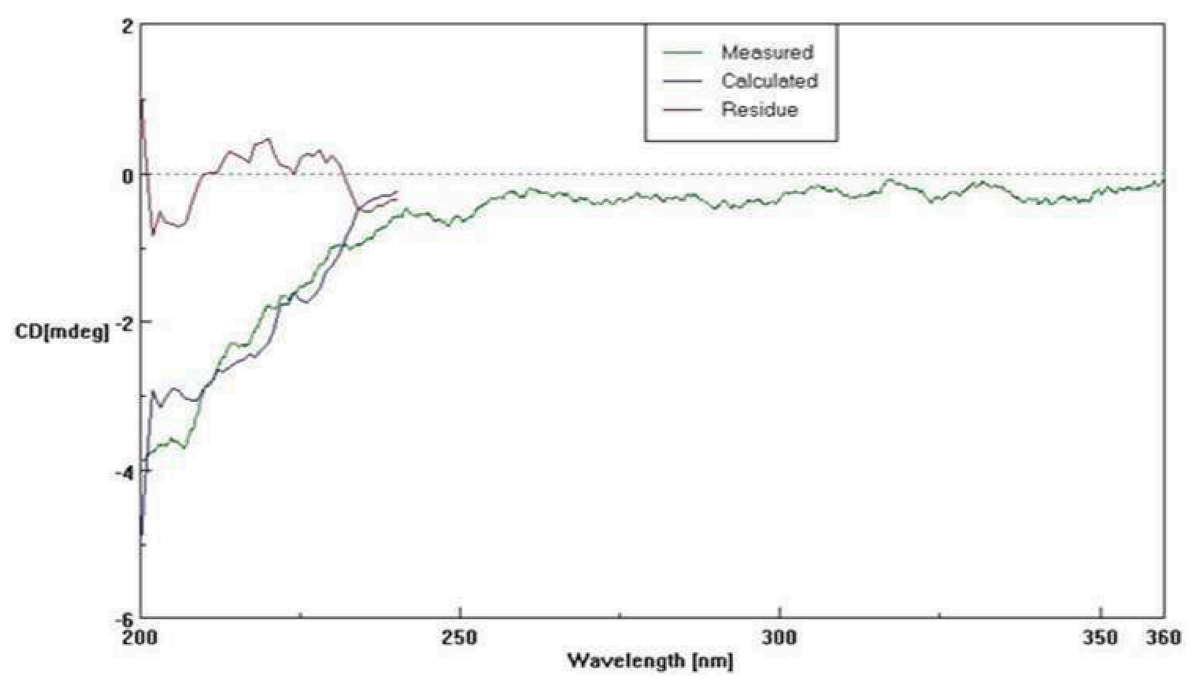

FIGURE 4 | Circular dichroism spectra of $A$. terreus NCFT 4269.10 amylase.

the most supportive vitamin for growth, generation of protein and production of $\alpha$-amylase by $P$. olsonii which also relates to the effect of vitamins for enhanced production of $\alpha$-amylase by A. terreus. Furthermore, Negi and Banerjee (2010) had also reported the function of different plant growth regulators on the production of $\alpha$-amylase and protease by $A$. awamori and concluded that indol-3-acetic acid (IAA) and Indole-3-butyric acid (IBA) enhanced the biosynthesis of enzymes secreted by A. awamori. The findings of Negi and Banerjee (2010) reported that napthelene acetic acid (NAA) and 2-4, D enhanced protease production but retarded biosynthesis of amylase which was also reported with the findings of $A$. terreus.

Different researches have been conducted using mixed substrates for the enhanced production of enzymes and other metabolites akin to the present study. Adeleke et al. (2012) have reported that mixture of orange bagasse and wheat bran was the best substrate for production of pectinase in SSF using Penicillium sp. Chutmanop et al. (2008) have also reported that rice bran alone has reduced porosity for agreeable SSF and could be more effective only when employed in combination with wheat bran for synthesis of protease by Aspergillus oryzae. With a suitable size of inoculum, nutrient and level of oxygen are adequate for ample growth and development of fungus and therefore, enhancement in the production of enzyme was observed. If the inoculum size is too small, scarce biomass will lower the secretion of enzymes. High inoculum size can also result in the depletion of oxygen and nutrient which may further hamper the secretion process of amylase. Roses and 
TABLE 7 | Fermentation kinetics of biosynthesized amylase.

\begin{tabular}{|c|c|c|c|c|c|c|c|c|c|}
\hline Optimum conditions & $\mathbf{Y}_{\mathrm{e} / \mathrm{s}}(\mathrm{U} / \mathrm{g})$ & $Y_{\mathrm{x} / \mathrm{s}}(\mathrm{g} / \mathrm{g})$ & $\alpha(\mathrm{U} / \mathrm{g})$ & $\beta(U / g / h)$ & $q_{c}(\mathrm{mg} / \mathrm{g} / \mathrm{h})$ & $d x / d t(g / L / h)$ & $\mathrm{d} P / \mathrm{d} t(\mathrm{U} / \mathrm{ml} / \mathrm{h})$ & $x(\mathrm{mg} / \mathrm{ml})$ & $\mu_{\max }(\mathrm{mg} / \mathrm{Lh})$ \\
\hline $\mathrm{pH}(7.0)$ & 0.379 & 0.012 & 31.63 & 0.003 & 5.833 & 0.395 & 0.019 & 1.2 & 12.5 \\
\hline Temperature $\left(30^{\circ} \mathrm{C}\right)$ & 0.400 & 0.030 & 14.28 & 0.004 & 5.833 & 0.297 & 0.015 & 2.8 & 18.75 \\
\hline Incubation period (96 h) & 0.286 & 0.018 & 15.88 & 0.002 & 3.751 & 0.417 & 0.021 & 1.8 & 29.16 \\
\hline Carbon source (Maltose) & 0.818 & - & - & 0.008 & - & - & 0.042 & - & - \\
\hline Organic nitrogen (Gelatin) & 0.450 & - & - & 0.004 & - & - & 0.024 & - & - \\
\hline Inorganic nitrogen $\left(\mathrm{NH}_{4} \mathrm{Cl}\right)$ & - & - & - & - & - & - & - & - & - \\
\hline Amino acid (Isoleucine) & 0.762 & 0.014 & 54.42 & 0.007 & 2.916 & 0.014 & 0.039 & 1.4 & 14.58 \\
\hline Metal ion $\left(\mathrm{Mg}^{2+}\right)$ & 0.466 & 0.136 & 3.42 & 0.004 & 28.333 & 0.485 & 0.024 & 13.6 & 141.66 \\
\hline Vitamins (Vit-E, 30 mg/100ml) & 20.24 & 0.17 & 119.05 & 0.211 & 35.416 & 8.854 & 1.054 & 17.0 & 177.08 \\
\hline Inoculum size (4\%, w/v) & 21.04 & - & - & 0.22 & - & - & - & - & - \\
\hline Moisture content $(70 \%$, w/v) & 23.96 & - & - & 0.25 & - & - & - & - & - \\
\hline
\end{tabular}

Guerra (2009) have reported that inoculum concentration of $1 \times 10^{7}$ spores/g of dry support is optimum for biosynthesis of amylase. Chimata et al. (2010) reported 5\% of inoculum size is suitable for production of amylase using a newly isolated species of Aspergillus. Owing to the lack of nutrients due to the over population of the microorganism, a reduced production profile of amylase was noticed with the higher range of inoculum size.

Moisture content plays an imperative function in solid state fermentation for enzyme production. The percentage of moisture content also varied according to the water holding potentiality of the substrates. Even though, the outcome of this study could not specify the genuine moisture content in the system, however, it gave a clue of the preliminary water content of PM which was essential to attain the maximum fungal growth and biosynthesis of enzyme. While working with Aspergillus species and A. awamori, Chimata et al. (2010), Negi and Banerjee (2010) reported 70 and $90 \%$ humidity for amylase production which is at par with the present finding obtained with A. terreus NCFT 4269.10 .

Complete down streaming of enzyme after successful completion of solid state/liquid static surface fermentation is one of the unavoidable parts of industrial production as it also decides the overall cost of production of enzyme. For recovery of contamination free enzyme from SSF, different extractants are generally employed. Aikat and Bhattacharya (2000) have reported that $0.6 \mathrm{M}$ phosphate buffer $(\mathrm{pH} 8.0$ ) was best in recovery of protease from Rhizopus oryzae using wheat bran as the substrate with $72 \mathrm{~h}$ of soaking time at the first extraction. They have also reported that Czapek Dox salt solution was better than that of distilled water. But in the present finding, distilled water was more efficient in enzyme recovery as compared to Czapek Dox solution. This could also be elaborated by the increase of hydrophobic interactions between enzyme and solid support which is still impregnated with the substrate.

The analysis of enzyme activity in the crude extract does not indicate either an isolated action or the presence of a multienzymic system working in synergy for degradation of the substrates. Therefore, purification and characterization of the purified enzyme is an important aspect of research which uncovers enzymatic complex components to unravel the mechanisms for degradation of substrates, optimum conditions for activity and regulation of enzyme synthesis. Identification of new hyperproducers of enzymes, their directed cultivation, enzyme recovery and its purification presents increasing consideration owing to their commercial expansion. In most of the cases, specific activity of the enzyme is increased after purification. Similarly, specific activity of $\alpha$-amylase was increased from 183.8 to $514.6 \mathrm{Umg}^{-1}$ in case of $M$. cinnamomea as reported by Han et al. (2013).

The molecular weights of most $\alpha$ - amylases produced by fungi were found to be in between of $45-65 \mathrm{kDa}$ ( $\mathrm{Li}$ et al., 2011). Han et al. (2013) reported the molecular weight of monomeric McAmyA which was found to be 60.3 and $57.5 \mathrm{kDa}$ by SDSPAGE and gel filtration, respectively which contradicts with the present findings. To describe the properties of a complex macromolecule like protein, elucidation of structural levels of organization of protein based on the extent of intricacy of their molecule is essential. Most often, straight, unfolded polypeptide chain attains a helical configuration to create the secondary structure. Further, the percentage occurrence of $\alpha$-helix, parallel $\beta$-sheets, $\beta$-turns, and random coils decide the stability and properties of the protein. Circular dichroism spectroscopy is an important method for appraisal of general secondary structure and observing folding in proteins. The features of $\mathrm{CD}$ spectra indicate that the purified $\alpha$-amylase possesses high $\beta$-sheet and $\beta$-turn contents and the purification steps yielded native secondary structure of $\alpha$-amylase. The secondary structure composition of glucoamylase was also studied from Aspergillus niveus by da Silva et al. (2009) which was at par with the crystal structures of glucoamylases from other Aspergillus species.

Maximum product yield, productivity of process and rate of substrate utilization finalize the fermentation economics. In view of this, fermentation kinetics plays a significant function in identifying the key cost breakdown points. Therefore, in this study, numbers of basic fermentation kinetics parameters were evaluated for developing a triumphant process which will be reasonably viable. As compared to the present study, 
similar type of observation was also reported by Iftikhar et al. (2010) for production of lipase from Rhizopus oligosporus var. microsporus.

\section{CONCLUSIONS}

This study reports the proficient exploitation of agro-industrial residues for the production of $\alpha$-amylase by both liquid static surface and solid state fermentations which are abundantly generated in developing countries like India. These economic substrates like, pearl millet $(\mathrm{PM})$ can serve as the source of carbon, nitrogen and other metabolites essential for the growth and maintenance of fungi and finally can produce biotechnologically relevant enzymes. In this study, different process parameters were optimized for the production of $\alpha$-amylase using PM as the substrate. The production of amylase was enhanced up to 60 -fold at $30^{\circ} \mathrm{C}$ for $96 \mathrm{~h}$ with the supplementation of vitamin $\mathrm{E}(30 \mathrm{mg} / 100 \mathrm{ml})$ to $\mathrm{PM}$ fermentation medium. Further, circular dichroism spectroscopic analysis confirmed the secondary structure of amylase. The secondary structure of amylase is rich in random coils $(36.8 \%)$ that contribute to the stability of the secondary structures of amylase. Hence, such uniqueness in stability would be one of the most preferred features of this amylase for suitable industrial exploitations. Nonetheless, such optimization of fermentation parameters would not only develop an eco-friendly protocol to rationalize the entire cost of production, but also help in

\section{REFERENCES}

Acourene, S., and Ammouche, A. (2012). Optimization of ethanol, citric acid, and $\alpha$-amylase production from date wastes by strains of Saccharomyces cerevisiae, Aspergillus niger and Candida guilliermondii. J. Ind. Microbiol. Biotechnol. 39, 759-766. doi: 10.1007/s10295-011-1070-0

Adeleke, A. J., Odunfa, S. A., Olanbiwonninu, A., and Owoseni, M. C. (2012). Production of cellulase and pectinase from orange peels by fungi. Nat. Sci. 10, 107-112.

Afifi, A. F., Kamel, E. M., Khalil, A. A., Foaad, M. A., Fawzi, E. M., and Houseny, M. M. (2008). Purification and characterization of $\alpha$-amylase from Penicillium olsonii under the effect of some antioxidant vitamins. Glob. J. Biotechnol. Biochem. 3, 14-21.

Aikat, K., and Bhattacharya, B. C. (2000). Protease extraction in solid state fermentation of wheat bran by a local strain of Rhizopus oryzae and growth studies by the soft gel technique. Proc. Biochem. 35, 907-914. doi: 10.1016/S0032-9592(99)00148-X

Alva, S., Anupama, J., Salva, J., Chiu, Y. Y., Vyshali, P., Shruti, M., et al. (2007). Production and characterization of fungal amylase enzyme isolated from Aspergillus sp. JGI 12 in solid state culture. Afr. J. Biotechnol. 6, 576-581.

Bernfeld, P. (1955). "Amylase $\alpha$ and $\beta$," in Methods in Enzymology, eds S. P. Colowick and N. O. Kaplan (New York, NY: Academic Press Inc.), 149-158.

Bhargav, S., Panda, B. P., Ali, M., and Javed, S. (2008). Solid-state fermentation: an overview. Chem. Biochem. Eng. Q. 22, 49-70. doi: 10.1080/07388550590925383

Chimata, M. K., Sasidhar, P., and Challa, S. (2010). Production of extracellular amylase from agricultural residues by a newly isolated Aspergillus species in solid state fermentation. Afr. J. Biotechnol. 9, 5162-5169.

Chutmanop, J., Chuichulcherm, S., Chisti, Y., and Srinophakun, P. (2008). Protease production by Aspergillus oryzae in solid state fermentation using agro-industrial substrates. J. Chem. Technol. Biotechnol. 83, 1012-1018. doi: $10.1002 /$ jctb effectual management of agro-industrial wastes. Therefore, this study represents a profitable maneuver, with simpler techniques for amendment of cultural parameters for improved production and recovery of $\alpha$-amylase.

\section{ETHICS STATEMENT}

This research work does not involve any human or animals. Therefore, the study is exempted from ethical approval procedures.

\section{AUTHOR CONTRIBUTIONS}

All authors listed, have made substantial, direct, and intellectual contribution to the work, and approved it for publication.

\section{ACKNOWLEDGMENTS}

The authors convey their gratefulness to the University Grants Commission, New Delhi, India for providing the financial support through Rajiv Gandhi National Fellowship Scheme with award letter Number F.14-2 (SC)/2008 (SA-III). The first author (BS) is also grateful to Dr. Keshab C. Mondal, Head, Department of Microbiology, Vidyasagar University, West Bengal, India for his kind permission and providing laboratory facilities to conduct some part of the research.

da Silva, T. M., Maller, A., Damasio, A. R. L., Michelin, M., Ward, R. J., Hirata, I. Y., et al. (2009). Properties of a purified thermostable glucoamylase from Aspergillus niveus. J. Ind. Microbiol. Biotechnol. 36, 1439-1446. doi: 10.1007/s10295-009-0630-Z

Ferreira Costa, M. A., and Peralta, R. M. (1999). Production of lipase by soil fungi and partial characterization lipase from a selected strain (Penicillium wortwanii). J. Basic Microbiol. 39, 11-15. doi: 10.1007/s10295-009-0630-Z

George, E., Tamerler, C., Martinez, A., Martinez, M. J., and Keshavarz, T. (1999). Influence of growth composition on the lipolytic enzyme activity of Ophiostoma piliferm. J. Chem. Technol. Biotechnol. 74, 137-140. doi: 10.1002/(SICI)10974660(199902)74:2<137::AID-JCTB997>3.0.CO;2-H

Glusker, J. P., Katz, A. K., and Boch, C. W. (1999). Metal ions in biological systems. Rigaku. J. 16, 8-16.

Hames, B. D. (1990). "One-dimensional Poly acrylamide gel electrophoresis," in Gel Electrophoresis of Proteins, eds B. D. Hames and D. Rickwood (Washington, DC: IRL Press, 1-147.

Han, P., Zhou, P., Hu, S., Yang, S., Yan, Q., and Jiang, Z. (2013). A novel multifunctional $\alpha$-amylase from the thermophilic fungus Malbranchea cinnamomea: biochemical characterization and three-dimensional structure. Appl. Biochem. Biotechnol. 170, 420-435. doi: 10.1007/s12010-0130198-y

Hoshino, T., Mizutani, A., Shimizu, S., Hidaka, H., and Yamane, T. (1991). Calcium ion regulates the release of lipase of Fusarium oxysporum. J. Biol. Chem. 110, 457-461.

Iftikhar, T., Niaz, M., Zia, M. A., and Haq, I. U. (2010). Production of extracellular lipases by Rhizopus oligosporus in a stirred fermentor. Braz. J. Microbiol. 41, 1124-1132. doi: 10.1590/S1517-83822010000400034

Ikram, U. H., Sikander, A., Qadeer, M. A., and Javed, I. (2003). Stimulatory effect of alcohols (methanol and ethanol) on citric acid productivity by a 2-deoxy Dglucose resistant culture of Aspergillus niger GCB-47. Bioresour. Technol. 86, 227-233. doi: 10.1016/S0960-8524(02)00172-4 
Jana, A., Maity, C., Halder, S. K., Das, A., Pati, B. R., Mondal, K. C., et al. (2013). Structural characterization of thermostable, solvent tolerant, cytosafe tannase from Bacillus subtilis PAB2. Biochem. Eng. J. 77, 161-170. doi: 10.1016/j.bej.2013.06.002

Khan, J. A., and Yadav, S. K. (2011). Production of alpha amylases by Aspergillus niger using cheaper substrates employing solid state fermentation. Int. J. Plant Animal Environ. Sci. 1, 100-108.

Kumar, A., Sachdev, A., Balasubramanyam, S. D., Saxena, A. K., and Lata. (2002). Optimization of conditions for production of neutral and alkaline protease from species of Bacillus and Pseudomonas. Ind. J. Microbiol. 42, 233-236. doi: $10.5897 /$ AJB 2014.13863

Laemmli, U. K. (1970). Cleavage of structural proteins during the assembly of the head of bacteriophage T4. Nature 227, 680-685.

Li, S., Zuo, Z., Niu, D., Singh, S., Permaul, K., Prior, B. A., et al. (2011). Gene cloning, heterologous expression and characterization of a high maltoseproducing $\alpha$-amylase of Rhizopus oryzae. Appl. Biochem. Biotechnol. 164, 581-592. doi: 10.1007/s12010-011-9159-5

Lowry, O. H., Rosebrough, N. J., Farr, A. L., and Randall, R. J. (1951). Protein measurements with the folin phenol reagent. J. Biol. Chem. 193, 265-275.

Mohamed, S. A., Azhar, E. I., Ba-Akdah, M. M., Tashkandy, N. R., and Kumosani, T. A. (2011). Production, purification and characterization of $\alpha$-amylase from Trichoderma harzianum grown on mandarin peel. Afr. J. Microbiol. Res. 5, 1018-1028. doi: 10.5897/AJMR10.890

Monga, M., Goyal, M., Kalra, K. L., and Soni, G. (2011). Production and stabilization of amylases from Aspergillus niger. Mycosphere 2, 129-134.

Negi, S., and Banerjee, R. (2009). Optimization of extraction and purification of glucoamylase produced by Aspergillus awamori in solid state fermentation. Biotechnol. Bioprocess Eng. 14, 60-66. doi: 10.1007/s12257-008-0107-3

Negi, S., and Banerjee, R. (2010). Optimization of culture parameters to enhance production of amylase and protease from Aspergillus awamori in a single fermentation. Afr. J. Biochem. Res. 4, 73-80. doi: 10.4103/0250-474X.65017

Norouzian, D., Akbarzadeh, A., Scharer, J. M., and Young, M. M. (2006). Fungal glucoamylases. Biotechnol. Adv. 24, 80-85. doi: 10.1016/j.biotechadv.2005.06.003

Nwagu, T. N., and Okoli, B. N. (2011). Growth profile and amylase hydrolytic activity of a thermophilic fungi Aspergillus fumigatus isolated from soil. Asian J. Biotechnol. 3, 46-57. doi: 10.3923/ajbkr.2011.46.57
Oser, B. L. (1965). Hawks Physiological Chemistry, 14th Edn. New Delhi: Tata McGraw Hill Publishing Co. Ltd.

Pandey, A., Soccol, C. R., and Mitchell, D. (2000). New developments in solid state fermentation; I-Bioprocesses and products. Proc. Biochem. 35, 1153-1169. doi: 10.1016/S0032-9592(00)00152-7

Roses, R. P., and Guerra, N. P. (2009). Optimization of amylase production by Aspergillus niger in solid-state fermentation using sugarcane bagasse as solid support material. World J. Microbiol. Biotechnol. 25, 1929-1939. doi: 10.1007/s11274-009-0091-6

Schaechter, M. (2009). Encyclopedia of Microbiology, 3rd Edn. Cambridge, MA: Elsevier Inc.

Sethi, B. K., Nanda, P. K., and Sahoo, S. L. (2013a). Isolation, identification and conservation of potent hydrolase producer from different soils of Odisha, India. Int. J. Pharma. Bio. Sci. 4, 89-100.

Sethi, B. K., Rout, J. R., Das, R., Nanda, P. K., and Sahoo, S. L. (2013b). Lipase production by Aspergillus terreus using mustard seed oil cake as a carbon source. Ann. Microbiol. 63, 241-252. doi: 10.1007/s13213-012$0467-\mathrm{y}$

Welch, R. M., and Grahm, R. D. (2004). Breeding for micronutriens in staple food crops from a human nutrition prospective. J. Exp. Bot. 55, 353-364. doi: 10.1093/jxb/erh064

Zeni, J., Cence, K., Grando, C. E., Tiggermann, L., Colet, R., Lerin, L. A., et al. (2011). Screening of pectinase-producing microorganisms with polygalacturonase activity. Appl. Biochem. Biotechnol. 163, 383-392. doi: 10.1007/s12010-010-9046-5

Conflict of Interest Statement: The authors declare that the research was conducted in the absence of any commercial or financial relationships that could be construed as a potential conflict of interest.

Copyright (c) 2016 Sethi, Jana, Nanda, DasMohapatra, Sahoo and Patra. This is an open-access article distributed under the terms of the Creative Commons Attribution License (CC BY). The use, distribution or reproduction in other forums is permitted, provided the original author(s) or licensor are credited and that the original publication in this journal is cited, in accordance with accepted academic practice. No use, distribution or reproduction is permitted which does not comply with these terms. 